\title{
0994. Development of ventilatory-induced lung injury depends on energy dissipated into respiratory system
}

\author{
M Gotti, C Chiurazzi, M Amini, C Rovati, M Brioni, A Cammaroto, S Luoni, C Bacile di Castiglione, G Rossignoli, \\ C Montaruli, K Nikolla, M Monti, D Dondossola, I Algieri, T Langer, M Cressoni, L Gattinoni
}

From ESICM LIVES 2014

Barcelona, Spain. 27 September - 1 October 2014

\section{Introduction}

Mechanical ventilation with high volumes/pressures induces ventilatory induced lung injury (VILI). During each breath, part of the energy transmitted from ventilator to respiratory system is given back as elastic recoil and part is dissipated into the respiratory system; this amount of energy is measured by the hysteresis area of the pressure-volume (PV) curve of the respiratory system. Total dissipated energy into respiratory system, or dissipated inspiratory potency, equals to energy dissipated during every single breath multiplied by the respiratory rate $(\mathrm{RR})$.

\section{Objectives}

To measure dissipated inspiratory potency throughout lung parenchyma and to asses if the reduction of the energy load into the respiratory system, obtained reducing RR, delays the development of VILI.

\section{Methods}

Ten piglets, after general anaesthesia induction, were ventilated at lethal tidal volume (TV), defined on strain $>2.5$ (which is known to cause lung oedema within 54 hours), but at different RR: 4 pigs at RR 3, 3 pigs at RR 6, 1 pig at RR 9 and 2 pigs at RR 15. We measured $\mathrm{PaO}_{2} / \mathrm{FiO}_{2}$ ratio, plateau pressure, and PV curve hysteresis in dynamic and static conditions at the beginning and at the end of the experiment and lung weight at the end of experiment.

Università degli Studi di Milano, Fisiopatologia Medico-Chirurgica e dei Trapianti, Milano, Italy

(c) 2014 Gotti et al; licensee Springer. This is an Open Access article distributed under the terms of the Creative Commons Attribution License (http://creativecommons.org/licenses/by/2.0), which permits unrestricted use, distribution, and reproduction in any medium, provided the original work is properly cited.

\section{Results}

Inspiratory potency set at the beginning of the experiment had a linear relationship with $R R\left(R^{2}=0.95, p<\right.$ 0.001) (Fig.1).

There were no differences in baseline conditions and in TV setting between groups. Piglets ventilated at RR 15 developed lung oedema (final lung weight: $550 \pm 28 \mathrm{~g}$ vs $287 \pm 49 \mathrm{~g}, \mathrm{p}<0.001) . \mathrm{PaO}_{2} / \mathrm{FiO}_{2}$ ratio and plateau pressure at the end of the experiment were different in piglets ventilated at RR15 (177 $\pm 9 \mathrm{mmHg}$ vs $437 \pm 77 \mathrm{mmHg}$,

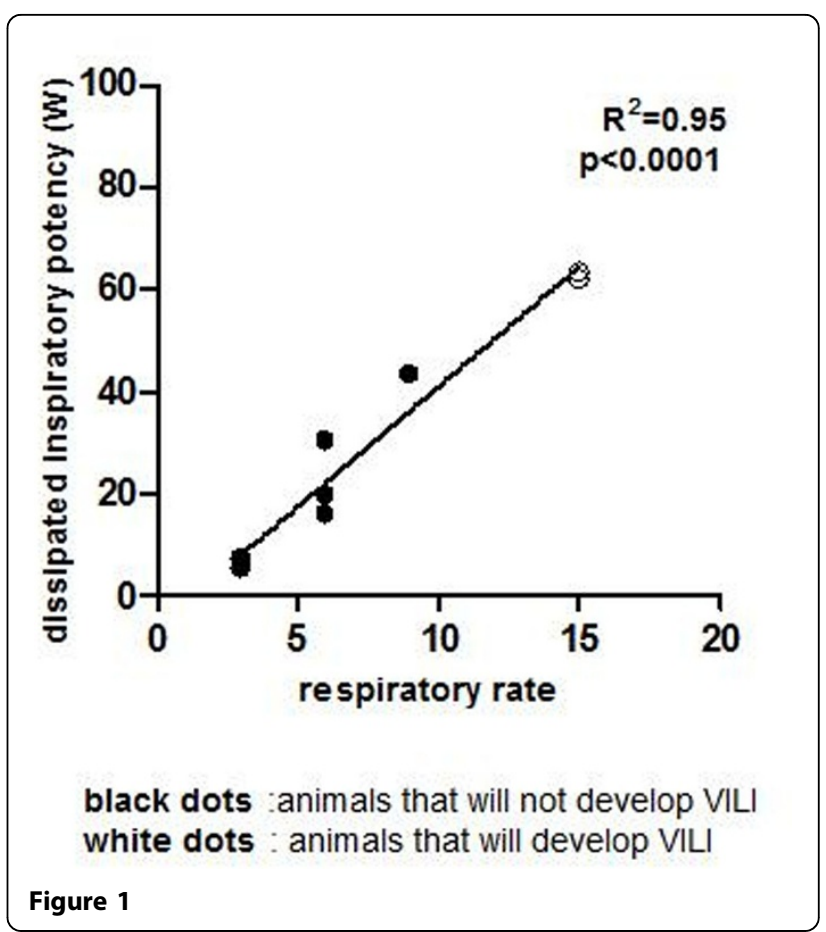

Figure 1 
$\mathrm{p}<0.01 ; 33 \pm 3 \mathrm{cmH}_{2} \mathrm{O}$ vs $22 \pm 5 \mathrm{cmH}_{2} \mathrm{O}, \mathrm{p}<0.05$, respectively), as compared to piglets ventilated at RR3, 6 and 9. Energy dissipated into the respiratory system increased only in pigs who developed lung oedema, from $63 \pm 1 \mathrm{~W}$ at the beginning to $110 \pm 28 \mathrm{~W}$ at the end of the experiment.

\section{Conclusions}

The development of VILI (lung oedema) depends on inspiratory potency dissipated into the respiratory system.

\section{Grant acknowledgment}

ESICM Bernard Drager Award 2012.

Published: 26 September 2014

doi:10.1186/2197-425X-2-S1-P79

Cite this article as: Gotti et al:: 0994. Development of ventilatory-

induced lung injury depends on energy dissipated into respiratory

system. Intensive Care Medicine Experimental 2014 2(Suppl 1):P79.

\section{Submit your manuscript to a SpringerOpen ${ }^{\mathcal{D}}$ journal and benefit from:}

- Convenient online submission

- Rigorous peer review

- Immediate publication on acceptance

- Open access: articles freely available online

- High visibility within the field

- Retaining the copyright to your article

Submit your next manuscript at $>$ springeropen.com 